\title{
The Roles, Challenges and Opportunities of Gadaa System in Resolving Water Conflict: The Case of Borana Oromo
}

\author{
Ketema Tafa Biratu', Obsa Mamo Kosa ${ }^{2}$ \\ ${ }^{1}$ Department of Civics and Ethical Studies, Madda Walabu University; Bale Robe, Ethiopia \\ ${ }^{2}$ Department of Afan Oromo and Literature, Madda Walabu University; Bale Robe, Ethiopia \\ Email: Ketematafa2014@gmail.com,obsakosa@gmail.com
}

How to cite this paper: Biratu, K. T., \& Kosa, O. M. (2020). The Roles, Challenges and Opportunities of Gadaa System in Resolving Water Conflict: The Case of Borana Oromo. Open Journal of Social Sciences, 8, 19-31.

https://doi.org/10.4236/jss.2020.82002

Received: January 6, 2020

Accepted: February 10, 2020

Published: February 13, 2020

Copyright $\odot 2020$ by author(s) and Scientific Research Publishing Inc. This work is licensed under the Creative Commons Attribution International License (CC BY 4.0).

http://creativecommons.org/licenses/by/4.0/

\begin{abstract}
The main objective of this study was to explore the roles, challenges and opportunities of Gadaa system on water conflict resolution in Borana Zone of Oromia. Qualitative method was used to achieve the objectives of the study. Relevant information was gathered from both primary and secondary sources. With regard to collecting the primary data, key informant interview; structured and semi-structured interviews, focus group discussions, and observation were used. The study revealed that the Gadaa system has been an egalitarian socio-economic, political and cultural system which had been practiced by the Oromo society for a long time. It had been guiding and regulating the life of the Oromo in relation to other peoples and their environment. The study also confirmed that Gadaa system has a great role in resolving conflicts that occur in a society by employing customary laws. The roles of women in conflict resolution within Gadaa system, the constraints faced Gadaa system's institutions while resolving conflicts and the main water organs of Borana Oromo are other findings of this study. The study also came up with the historical roles of Gadaa system, procedures of conflict resolving and social structures of the Borana Oromo society. Lastly, the study verified the Borana Oromo's view of conflict. Though most of the key informants viewed conflict as inevitable and natural which could prevail in any society on the contrary, few of them viewed conflict as bad and destructive. The findings further showed the opportunities of practicing Gadaa system for Ethiopia as well as for Oromo community.
\end{abstract}

\section{Keywords}

Gadaa System, Indigenous Institution, Water Conflict, Borana Oromo 


\section{Introduction}

Ethiopia has a strong cultural heritage and various indigenous communities based social institutions or self-support systems that play a greater role in conflict resolutions, communities' well-being, stability and security (Abebe, 2012). These indigenous institutions are very useful for conflict management mechanisms as they allow communities to handle their problems in their own way. The people of Oromo have an extensive and very rich culture and tradition which have been accumulated for centuries and have been handed down from generation to generation. The culture of the people is deeply rooted in the Gadaa system which is a democratic political, economic and social system. The Gadaa system is a complex and holistic system that occupies the political, social and economic aspects of the Oromo people's lives and organizes them into groups that assume different responsibilities.

The practice and experience of the Oromo people as manifested in the Gadaa system is surely very beneficial to the future generation. The interconnectedness and overlapping features of Oromo cultural values particularly Gadaa system's conflict resolving institution constituted the unity of complex systems of knowledge. Though characterized as man-made outlook, there is no easy separation between the sacred and the profane, matter and spirit, the communal the individual, and components of the Oromo values. As far as each and every system of knowledge is interdependent, the press of a single system of knowledge could affect the rest. Thus, there is a growing need to maintain the unity of Oromo's all systems of knowledge (Abebe, 2012).

The Gadaa system is the constitution of the Oromo society through which the society administered, defended their territory, maintained and developed their economy and it is the self-sufficient system that influenced every aspect of Oromo society, from politics to religion until recently.

Conflict is not a new phenomenon in the history of human beings. It is different things to different people. It always exists as long as human beings live together and it is an inescapable human experience (Osi, 2008). Conflict is a condition of disagreement in an interaction process and usually occurs as a result of clash of interest between the parties involved in some form of relationship. Competition over natural resources, including water, is often viewed as a driver of conflict and has emerged as a key component in many current and past conflicts. If it is not well taken and resolved early, conflict between or among individuals will grow up and become treating to national security, peace and stability which are the basic parameter to measure the development of a nation (Abebe, 2012). According to Francis (2006), conflict is by definition natural and unavoidable part of human existence, i.e. a nature disagreement resulting from individual or groups that differ in attitude, beliefs, values or needs. As there is the notion of society and the very existence of peoples, there is obviously conflict no matter the extent as well as the source of it. In fact, one cannot separate conflict from humankind. It is impossible to see them independently; they are al- 
ways together making two faces of the same coin. It is unconceivable to think a society without conflict (Abebe, 2012).

Water is an essential ingredient for human security and sustainable development. It is a fundamental resource; indispensable to all forms of life on earth. It is a simple truth that "water is life." There is almost no living thing that could have life without water. Reliable freshwater resources are crucial to human and environmental health, as well as for economic development. Access to water is therefore a question of "life or death" which easily becomes an emotionally charged conflict. Water plays an important role in many traditional and religious customs expands its emotional value. Water is also an important element for social stability and the civilization depends largely on its availability. Given its centrality to human life, it is not surprising that water management is complex and that water-related interests are frequently questioned. Access to water in sufficient quantity and quality can drive competition where interests are perceived as incompatible. It can also increase cooperation where mutual interest can be found. Competition over this precious resource could increasingly become a source of tension and even conflict among states and sectors. Whenever there is competition for water there is a risk of it degenerating into conflict. There is a pressing need to better understand water as it relates to all levels of conflict.

Water conflicts have a long history and continue to be global and regional problems. In recent years a shift in perception has begun to take place among the world's leading authorities on water. This shift involves the opening of spaces for indigenous institutions voices to contribute towards the search for effective water governance approaches (Indigenous water Initiative, 2003). Water conflict occurs at different interdependent levels like local, national, and international. The main causes of water conflict at these levels include; socio-economic, political and environmental factors. Many analysts who write about water politics, especially those who obviously address the issue of water conflict assume that scarcity of such critical resources drives people to conflict.

Several researches have been done on indigenous conflict resolution mechanisms in Ethiopia. These among others include such as Gereb in Wajerat (Tigray) and Mablo in Ab'ala of Afar (Kelemework, 2000); Abagar in Southern Wollo (Netsanet, 2006), Michu in Metekel (Tsega, 2002), Awassia in Walayta (Mellesse, 2008), Afocha in Harar (Biruk and Jira, 2008), Jarsumma and Haffi Hamee in Oromia (Assefa, 2005), Guma in Waliso Oromo (Dejene, 2007).

However the above researches were predominantly relied on the nature, process, role of the elders, as well as the actors in the indigenous conflict resolution mechanism. However, much emphasis has not been given to the role of Gadaa system in water resources conflict resolution. This does not mean that research is not undertaken on Gadaa system. For instance, Professor Asmarom Legesse (1973 and 2000) focused on the study of Gadaa system as political institutions and studied the nature, structure and principles of the institutions. He 
did not focus on the role of the system in water resources and thus did not treat in detail the role of the system in conflict resolution. However, this study is intended to assess the issues dealing with the roles, constraints and opportunities of Gadaa Oromo System of water conflict resolution in Borana zone in Oromia (Figure 1).

\subsection{Statement of the Problem}

Africans, as any other people elsewhere, have their own philosophy of life. They have a different culture by which they see and interact themselves. The priority of African traditional conflict resolution mechanisms is to bring about sustainable collective social stability and harmony. After all, Ethiopia is believed to be the home of more than 80 ethnic groups. They have their own different backgrounds, languages, and cultures. These various ethnic and cultural groups for so long years have developed their own unique political or administrative, economic, social and judicial systems. They had been able to sustain themselves without necessitating to have copied the Western modes of governance nor is their mechanisms of conflict resolution (Abebe, 2012).

Accordingly, the Oromo people settle various disputes through indigenous institutions that they have developed through long years of experience (Osi, 2008). Several researches were done on indigenous conflict resolution mechanisms in

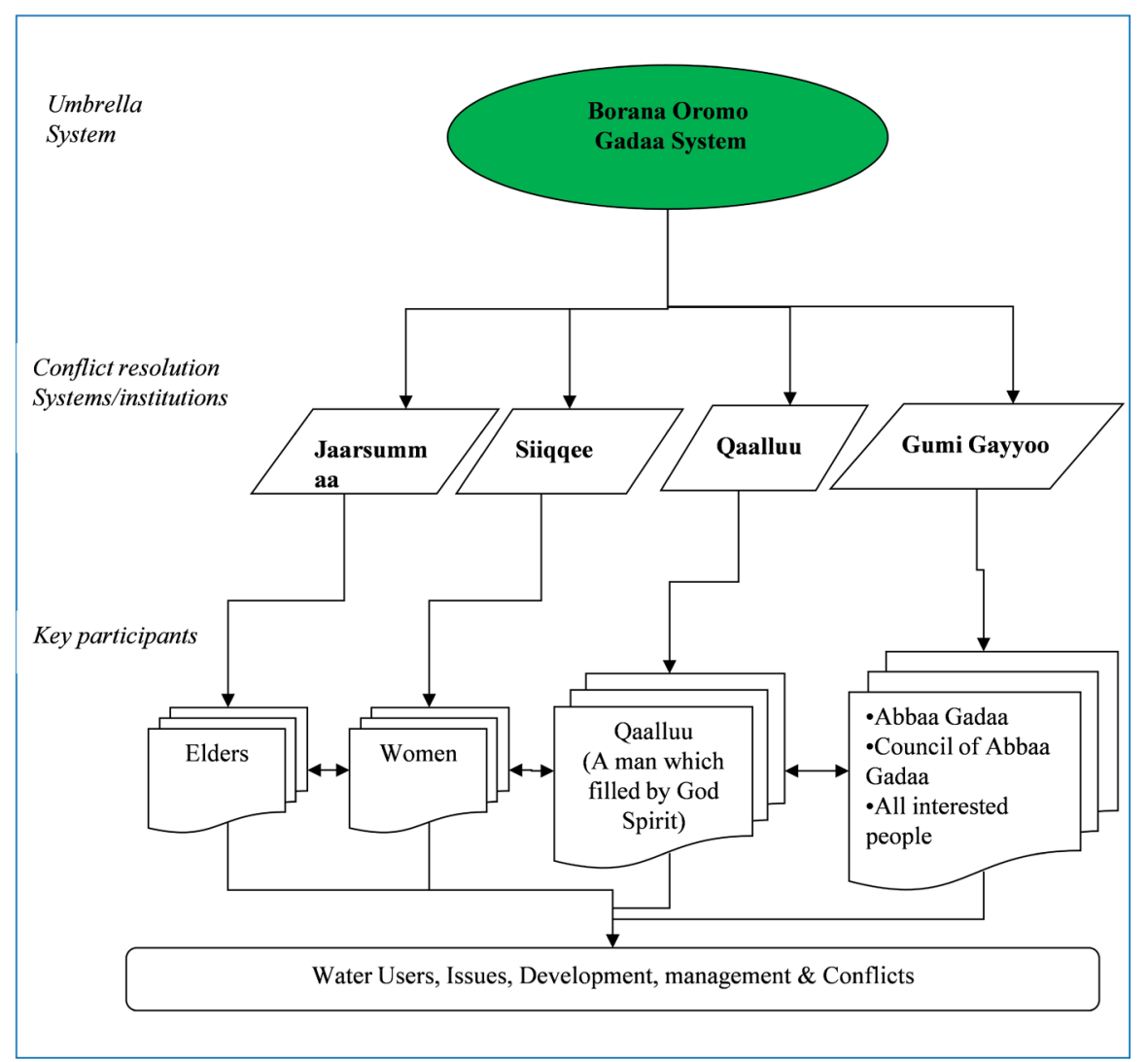

Figure 1. The conceptual framework of Conflict resolving Institutions in Borana Oromo Gadaa System. 
Ethiopia. Particularly, several researches have been done with respect to the nature, process, role of the elders, as well as the actors in the indigenous conflict resolution mechanism. However, much emphasis has not been given to the role of Gadaa system in water resources conflict resolution.

\subsection{Significance of the Study}

The study would be significant from the following perspectives. First, it would provide valuable information and understanding about the roles of Gadaa system conflict settlement mechanism plays among Oromo people. Second, it would reveal the preference of people related to conflict settlement mechanisms and the rationale behind it. Third, the finding of the study believed to be used by the concerned bodies to consider and preserve Gadaa system's indigenous knowledge and values. Further, the result of the study had contributed to the limited literature and assesses the challenges and Opportunities on the roles of Gadaa system conflict resolution mechanisms.

\subsection{Objectives of the Study}

The main objective of the study was to assess the roles, challenges and Opportunities of Gadaa system in resolving conflict on water resources uses. The specific objectives were to:

- Identify Gadaa system's conflict resolution institution in Borana Oromo;

- explore the processes, procedures and challenges followed by Gadaa system to solve conflicts;

- examine the role of women in the process of conflict resolutions in the study area and

- investigate the roles of Gadaa system in resolving of conflict on water resource uses.

\section{Materials and Methods}

Borana zone is one of the administrative zones found in Oromia region of Ethiopia. It is made up of 13 districts. Yabello is the capital town of the Borana zone and lies $570 \mathrm{~km}$ south of Addis Ababa. It is located at the southern edge of the country and bordered by Kenya in the South, Somali region of Ethiopia in the South East, Guji Zone of Oromia in the East and North East, and Southern Peoples, Nations and Nationalities in the West.

The land is largely covered with light vegetation of predominantly pod-yielding Acacia species of low forage value. The ecological conditions favor pastoralism more than farming or they are pastoralist because the ecological condition is more favorable for pastoralism than farming. Therefore, livestock husbandry is the economic main stay of the area. Borana has deep respect for pastoralism. A person who doesn't have cattle is not as respected as the one who do in Borana society. Since cattle have social, economic and cultural values, those individuals who have large herd of cattle are respected and socially accorded high position 
(Fikadu, 2009). The short-lived drainage system of the Borana zone is located within the Genale-Dawa River basin.

The Borana Oromo are numerically the dominant ethnic group inhabiting the Borana lowlands. The researchers selected three woreda as a research site from where the necessary data were collected. The researchers intentionally selected those three woreda because of some convincing reasons. These are Arero, Dire, and Yabelo. In the first place Yabelo is the seat of the zonal administration, so it would be easy to consult the zonal culture and tourism department frequently. On the other hand, since it is the zone's center, it is thought to be relatively better secured than other woreda. The left two woreda are the woreda where Borana Oromo Gadaa system have been most strongly maintained, and which the Borana Oromo community regard as their cultural center. Many traditional practices particularly Gadaa system's ceremonies presently functioning in those woreda (Figure 2).

\subsection{Research Design}

The research is designed and employed qualitative approach. To collect the necessary and relevant data, the instruments employed for this study were key informant interviews, focus group discussion, and observation. Data sources included both primary and secondary data. The primary sources of data was community elders, Abbaa Gadaas, both male and female youth, women and culture and tourism staff members of the selected woreda whereas the secondary

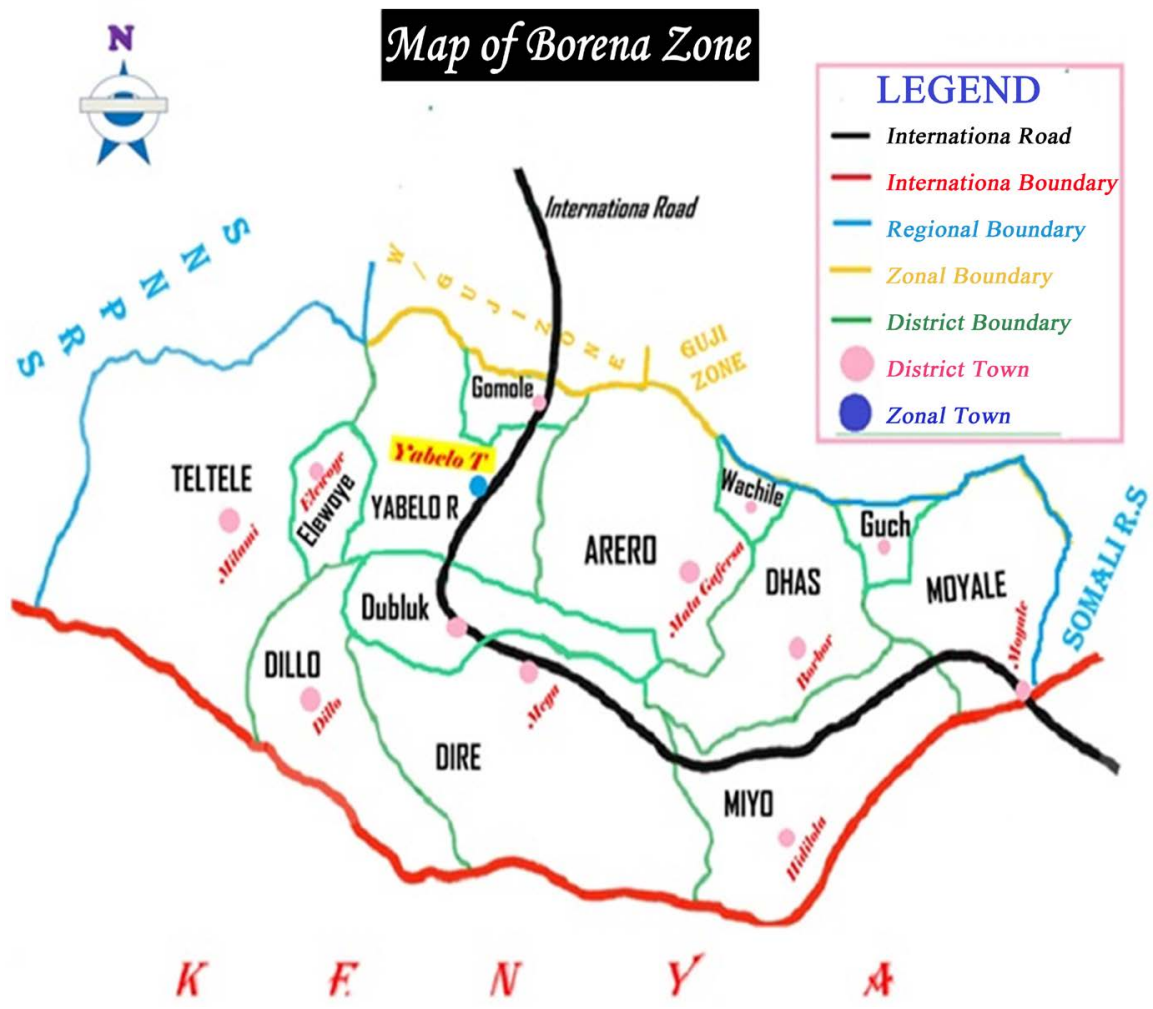

Figure 2. Map of Borena zone. 
sources included the relevant and related literatures, books and journals to enrich the primary data. Interviews provided chance for informants to express the situation in their own ways. This research therefore, significantly relied on key informant interviews for its primary data. Interviews were conducted with community elders, experienced women, culture and tourism offices staff members of selected woreda, water governance body and Abbaa Gadaa of Borana Oromo.

Furthermore, data were generated from Focus group discussion by taking into consideration that, it overcome the inconsistencies that sometimes occur between what people say and what people do. This method was well-matched also in drawing up the respondent's attitudes, beliefs, feelings, experiences and responses regarding the issues understudy and in gaining multiple views about the issue of concern. Thus the researchers arranged four focus group discussions with respondents from different social groups to look at concerns of different individual regarding the objectives of the research and to assess particularly both male and female youth's level of understanding the roles of Gadaa system.

\subsection{Methods of Data Collection}

The required data were generated from people who have direct experience of Gadaa system. In other words, it was those peoples who have rich experience on the issue under study and those who engaged on conflict resolution, administration and water resource governance that was selected to gather the desired information. Thus, the partially retired Abba Gadaa, elders, both male and female youth, experts of tourism and culture of Borana Oromo and government officials was consulted with the intention to address the research questions. Thus, some of the informants were identified purposively based on their knowledge about the Borana Gadaa system and pertinent issues, while others were identified through a snowball sampling procedure.

\section{Results and Discussion}

\subsection{Practices of Gadaa System}

Gadaa system had been practiced by the Oromo people from time of immemorial. However, slight differences are observed in the ways they practice across Oromo communities (Aredo, 2002). As of their relative isolation from external influences, Gadaa system is still well functioning in Borana than the Oromo's in the other areas. Gadaa system of Borana Oromo has the practical values in different social, cultural, political and environmental dimension. Gadaa system dealing with issue such as conflict resolution, peace justice and serving as a mechanism for enforcing moral conduct, building social cohesion and expressing forms of community culture (Hinew, 2005).

\subsection{Procedures of Water Conflict Resolving in Borana Oromo Communities by Gadaa System}

A conflict is driven by water resources when an incompatibility arises concern- 
ing water as a consumable resource to be managed, including water quality or allocation (Chimede, 2005).

Conflict resolution is directed at understanding conflict processes and alternative non-violent methods that help disputing parties reach mutually acceptable positions that resolve their differences. Conflict resolution is seen by Miller (2003) as "a variety of approaches aimed at terminating conflicts through the constructive solving of problems, distinct from management or transformation of conflicts (Neway, 2010)".

The process of conflict reconciliation among the Borana Oromo is headed by community's elders. The community elders are selected mainly after conflicts have broken out. If the parties in the conflict are unable to reach an agreement, the elders are repeatedly begging them to reach an agreement (Adem, 2014). At the time when the parties in conflict agree to solve their problems by reconciliation, the elders those who know deeply the principles of Gadaa are deeply start having meeting to solve conflicts peacefully. In the process, where the disputants refuse to admit their guilty, the elders try to persuade them using different mechanisms.

The place for the final reconciliation at the river side (water body) is carefully chosen because, water as Oromo community faith recognized as the symbol of peace making. Elders also can refer the cases to Abbaa Gadaa and his council when a decision cannot be solved at their level. If the issues are not still solved at the level of Abbaa Gadaa, the problem may be appealed to the main assembly called Gumii Gaayyoo (the higher institution of Gadaa system of Borana Oromo administration).

Conflict resolution process in the Borana Oromo community is not an issue of winning and losing, the case for one or the other party (Tafere, 2008). Upon the procedures and attainment of resolution, none of the disputants is acknowledged winner or loser because, the goal of conflict resolution in Borana Oromo community context is the reconciliation of the parties involved in conflict (Tafere, 2008).

\subsection{The System of Jaarsa Araaraa}

The System of Jaarsa Araaraa is the mechanism of dispute settlement among the Borena Oromo society. The terms jaarsa and araaraa, literally mean elder and reconciliation respectively. Thus, jaarsa araaraa refers to reconciliation through elders. In this context, the term elder does not necessarily show age, but role. Any person who plays the role of mediator at a given araara proceedings is jaarsa regardless of his age Dejene (2002). Jaarsummaa system is mainly characterized by the presence of a neutral third party who mediates between the disputants. The role of a third party as a mediator varies in degree from case to case and the nature of the relationships of persons in the dispute. Where the disputing parties have no serious problem in negotiating through face-to-face discussion, but are unable to settle their own case on their own, a mediator simply facilitates so that 
the negotiators to arrive at a decision on which both parties agree. A mediator or mediators often consult disputing parties by referring to norms, values, and rules to move them to an acceptable end (Chimede, 2005).

The jaarsa araara may go further up to proposing solutions. On the other hand, a third party plays a more active role similar to what call arbitrator. The role of the third party as an arbitrator evolves either from its failure as a mere mediator, or required from the very outset owing to the nature of the issue in conflict. Where the disputants have serious problems of communication, the third party plays a pivotal role. Jaarsummaa is a system in which the group of jaarsaas (literally meaning elders) involves in the process of reconciliation between conflicting individuals or groups (Mamuye et al. 2011). Among the Oromo, the mechanism of conflict resolution in which the neutral third party involves to mediate between disputants is known as jaarsummaa system. It is the system of elders arguable in which the role of mediators ranges from mere facilitators of a particular negotiation to arbitrators (Dejene, 2007). Jaarsummaa is "a customary court/legal institution entrusted to resolve all types of conflicts that arise within a group who abide by a body of unwritten customary rules" (Areba \& Berhanu, 2008). In the jaarsummaa process, the elders mainly aim at bringing about restoration (araara) of the severed relationships between the parties (Tarekegn \& Hannah, 2008).

In general, reconciliation and arbitration through Oromo elders has been part of the Gadaa system from the ancient time up to present time by which the Oromo peoples have lived a stable life by keeping their unity.

\subsection{Gumii Gaayyoo Assembly}

Gumii Gaayyoo is the most inclusive event in Borana Oromo political life. Gaayyoo is the assembled representatives of the entire society of Borana in combination with any individual who has the initiative to come to the ceremonial lands. Gumii Gaayyoo assembly held once in every eight years. That means any elected Abba Gadaa held on the Gumii Gaayyoo assembly once after four years of holding power. Conflicts that did not solve at lower stages (at elders level and Gadaa level) do get solution at Gumii Gaayyoo assembly (Asmarom, 1973).

Asmarom (1973) elaborate further, Gumii Gayyoo is the most important institution that made up of many councilors, assemblies drawn from different sections of the Gadaa system institution as well as ordinary citizens who have the ability to express their ideas on issues of communities' concern and has interest to travel to the place where the assembly is held (Asmarom, 1973).

\subsection{The Roles of Women in Gadaa System Conflict Resolution}

In Borana Oromo Gadaa systems women have the lion's share of conflict resolution. Despite the fact that the role of women in the overall livelihood improvement and efforts is not well considered in most of Ethiopian societies, it is becoming obvious that almost no effort excluding the honest involvement of 
women can be achieved as required. Women in Oromo society in general and in Borana Oromo particularly assumed as the innocent and peace loving (Asmarom, 2000).

Women have special skills and power in settling conflicts. The prominent roles the women play in conflict resolution starting from fighting the violation of their personal right up to resolving inter-clan conflicts (Baissa, 2004).

\subsection{Opportunities of Practicing Gadaa System in Borana Oromo}

This topic discusses the major opportunities of using Gadaa system among the Borana Oromo relying on the information gathered from the informants using the designed tools. Like that of other peoples of Ethiopia, the Oromo people particularly Borana Oromo have exceeding abundant culture that has been accumulated for a long period of time from generation to generation. This well cultivated culture is deeply rooted in the Gadaa system that has been shaping and guiding the mode of governance, socio-economic conditions and world view of the people (Baissa, 2004).

As culture and tourism offices staff member of selected woreda interviewees' responded, the recent inscription of Gadaa system as an intangible cultural heritage of the world by the United Nations Educational, Scientific and Cultural Organization's (UNESCO) provide very great opportunities for the country and particularly for Oromo people to gives more guarantee to protect and preserve the Gadaa system. As they responded, the inscription is not only promoting, conserve and preserve the system but also it give all people big responsibility of safeguarding and cultivating other various cultures.

Abbaa Gadaa Borana said that, now the world had learnt that in the old days Oromo people had been using a system that regulates the political, economic, social and religious activities and dealt with issues such as conflict resolution and protecting the rights of citizens especially women. The recognition of the Gadaa system, a political, economic and social system with a long history with which the people of Oromo have been governing themselves in a democratic way is expected to contribute a lot in the effective of the tourism industry of the country.

\section{Conclusion}

The most widely used mean of conflict resolution has its history in the day to day life of Ethiopian since its early history. The customary ways of conflict settlement are inherent in each ethnic group which is still evident in many parts of the Ethiopian country as a basic way to settle conflicts. Compared to its roles much has not been done to incorporate these conflict settlement methods in the legal system of the country (Baissa, 2004).

Conflict is indispensable part of social interaction since the inception of human settlement as different scholar elaborated. It arises if disagreements come up from difference in the interests, ideas, ideology and it happens between individual or among group. Whatever the causes and sources of conflict, all societies 
have their own ways resolving conflicts culturally.

The Oromo people have a well-known democratic system, called Gadaa system administration which plays a great role in the political, social, economic, cultural and in the religion affairs of Oromo people (Mamuye, 2011). The Oromo people particularly Borana Oromo used the Gadaa system as constitution of their government.

Gadaa system conflict resolution mechanism has so many roles in terms of cost effectiveness, time and energy saving and long lasting or sustainable solution for conflicting parties. It also plays a great role as the conflicting parties are active participants, raising public interest and awareness; gives rise to permanent resolution of conflict as well as it employs non-discriminatory approach on its conduct.

\section{Recommendation}

Taking into considerations of the findings obtained and conclusions drawn, the researcher stated the following recommendation:-

- Conflicts are inevitable and unavoidable. What is important is to respond to them properly. Gadaa system of Borana Oromo and its indigenous conflict resolution institutions (Elders, women, and Gumi gayyoo) play great role effectively in doing so. Thus, it should be encouraged, supported, appropriately recognized and given equal treatment with the modern court system.

- To further develop the culture of the Oromo people, new generation have to first deeply understand the roles of Gadaa system of this great people.

- The government and all concerned organ must realize and promote the roles of Gadaa system conflict resolution in the development of democratic political culture.

- The federal government as well as the regional government should be spelled out the Gadaa system's conflict resolution mechanisms particularly on water issues during the planning stage of water resource management policy.

- Consideration should be given to the potential and roles of the Gadaa system of Borana Oromo to settle conflicts sustainably.

- The government organs, concerned individuals particularly Borana Oromo must understand the roles of the existing traditional especially Gadaa system water conflict settlement mechanisms and they should build on their know-how for water structure management.

- The necessary measures should be taken from local and federal government to properly address the constraints associated with the Gadaa system's conflict resolution mechanisms.

- The state constitution of Oromia region should be amended to include express provision which recognizes the Gadaa system's conflict resolution institutions through adequately demarcate the state's involvement.

- Though the researchers attempted to assess the roles, challenges and opportunities of Gadaa system conflict resolution with main emphasis on water 
resources in Borana Oromo community, it is hardly possible to say the study is comprehensive enough. Therefore, the researchers would like to underline the need for further research.

- To meet all necessary, innovative water laws must be designed not only to facilitate and achieve efficient allocation of resources and environmental protection, but also to aim towards the attainment of cultural uses, social, economic and other national goals.

- The regional states should recognize and implement the basic principles and values of the Gadaa system, such as processes to ensure the peaceful transfer of power, fixed terms in office, fair access to power by all citizens and peaceful conflict resolution mechanisms.

- A healthy policy framework, norms and standards that will define the place and roles of Indigenous institutions conflict resolution, like the Gadaa system should introduce in country's constitution.

- The regional government needs to provide a statutory framework that enables the Gadaa system's conflict resolution institutions to work to its full capacity.

- The roles of Gadaa system need to be figure on the agenda of the country as one of a vehicle for development. Thus, government need to ensure that Gadaa system is not ignored when designing overall development plan.

\section{Conflicts of Interest}

The authors declare no conflicts of interest regarding the publication of this paper.

\section{References}

Abebe, A. (2012). Indigenous Mechanisms for the Prevention and Resolution of Conflict: The Experience of Oromo in Ethiopia, Addis Ababa, Ethiopia.

Adem, J. (2014). Women and Indigenous Conflict Resolution Institutions in Oromia. Experience from Siiqqee of the Wayyuu Shanan of Arsi Oromo: In Adami Tulluu Gidduu Kombolcha District of Oromia Regional State. M.A. Thesis, Addis Ababa, Ethiopia: Addis Ababa University.

Aredo, D. (2002). The Root Causes of Conflict among the Southern Pastoral Communities of Ethiopia: A Case Study of Borana and Degodia. In Conflict in the Horn: Prevention and Resolution. Addis Ababa.

Baissa, L. (2004). The Oromo Gada System of Government: An Indigenous African Democracy, New York, USA.

Hinew, D. (2005). Historical Significance of Some Major Gadaa Centers in Oromia. Department of History, Addis Ababa University.

Mamuye, T. (2011). The Siinqee-Women's Institution for Conflict Resolution in Arsii. In Customary Dispute Resolution Mechanisms in Ethiopia. Addis Ababa.

Osi, C. (2008). Understanding Indigenous Dispute Resolution Processes and Western Alternative Dispute Resolution: Cultivating Culturally Appropriate Methods in Lieu of Litigation.

Professor Asmarom (1973). Gadaa: Three Approaches to the Study of African Society. 
New York: Free Press.

Professor Asmarom (2000). Oromo Democracy: An Indigenous African Political System. Asmara: The Red Sea Press, Inc.

Tafere, K. (2008). Indigenous Institutions of Conflict Resolution among the Ab'ala Afar of North Eastern Ethiopia. M.A. Thesis, Addis Ababa, Ethiopia: Addis Ababa University. 